of detecting the disease cheaply and reliably, and how to assess the effectiveness of new drug combinations, go unanswered.

But it isn't just the lack of funding that makes TB researchers feel like the poor relations in the global health family. Difficulties in working alongside the better-funded efforts to tackle AIDS permeate many aspects of TB prevention, treatment and research at all levels, from the clinics of South Africa's most impoverished townships to the headquarters of the WHO in Geneva.

Treatment for TB is commonly dispensed in developing countries through long-established public-health clinics, whereas AIDS treatment often comes through separate, dedicated facilities. This division does nothing for the patients suffering from both diseases.

As for research, there has been inadequate collaboration between the relatively small number of scientists who devote their careers to studying TB and the far larger community working on AIDS. Yet both groups could surely benefit from each other, especially with regard to improving their understanding of the interaction between the two diseases.

But it is perhaps at the bureaucratic level that this division is most pronounced. The offices dealing with AIDS and TB at the WHO, for example, have historically enjoyed a difficult relationship characterized by rivalry rather than cooperation.

Steps are being taken to improve this sorry state of affairs. Treatment is successfully being integrated on the ground in South Africa and elsewhere, usually one clinic at a time. Researchers from the two fields are working together to study 'immune reconstitution syndrome', a little-understood phenomenon that affects those taking drugs for both TB and AIDS. And at the WHO, outmoded blueprints for the diagnosis and treatment of TB are being revised, with the assistance of staff with backgrounds in HIV treatment. Thanks to the intervention of the Gates Foundation and others, drug and vaccine candidates for $\mathrm{TB}$ are entering trials at a reasonably healthy rate for the first time in decades.

There is an overriding need for greater collaboration between AIDS and TB prevention, treatment and research, and this should be implemented at the grass roots wherever possible. But this common-sense remedy isn't, on its own, going to overturn a deeply ingrained division that has taken shape over many years.

Global health provision only really changes when leadership is forthcoming, not just from international organizations but from governments, specifically those that are in a position to lead - in this case, those of the United States, the European Union, India and South Africa. World Tuberculosis Day on 24 March seeks to draw attention to the disease, and provides an opportunity for governments to do just that, by acknowledging the problem and stating what they intend to do about it.

\section{The ends of the Earth}

\section{International Polar Year 2007 can leave an imprint.}

T he last time there was an International Polar Year (IPY), the world was a very different place. In 1957, at the height of the cold war, the poles were less a place for intriguing scientific discoveries than for political manoeuvring between the Soviet Union and the United States. Yet 1957-58 marked the third International Polar Year (the first two were in 1882 and 1932) and the first International Geophysical Year - a significant landmark, with hindsight, for global scientific collaboration.

The International Geophysical Year yielded several great scientific discoveries, many of which were inexorably linked to cold-war imperatives. James Van Allen discovered the belts of radiation surrounding Earth with the first US satellite, Explorer I, sent up in response to the Soviet Union's Sputnik. And the US nuclear submarine Nautilus, on a top-secret voyage, became the first vessel to visit the North Pole under the ice.

This time round, the political context of the IPY is dominated by climate change. Tasks for the coming year include taking detailed measurements of melting sea ice in the Arctic (see page 133) and a hunt for the best records yet of past climate change in the Antarctic (see page 126).

But scientists seeking support for these missions have got off to a rocky start, at least in the United States, as the result of a budget impasse that briefly froze spending for the National Science Foundation at 2006 levels. By January, last-minute negotiations had yielded an extra \$334 million for the agency, including money it needs to

grant IPY proposals in the coming year. But many of the scientists involved are still awaiting confirmation that their projects will go ahead, and their frustration is becoming palpable.

Elsewhere, the outlook is more certain. Canada, for instance, has pulled together all the funding for a large international programme to study the circumpolar flaw lead, an area of water that separates the bulk of the Arctic sea ice from the ice at the coast. Canada has also taken a welcome lead in involving indigenous peoples in its research programmes. The interdisciplinary ArcticNet project, based at the Université Laval in Quebec, aims to disseminate information gleaned about changes in the polar regions to the communities that are most directly affected.

These international efforts may alleviate some of the problems that have long plagued Arctic research, such as the decline of meteorological monitoring stations. The collapse of the Soviet Union has caused numerous observing stations to close. One target for the IPY

"The polar year
represents the
best chance to get
climate-monitoring
networks up and
running."
is to upgrade some key sites and monitor them over the long term; the US National Oceanic and Atmospheric Administration, for instance, is upgrading its climate-monitoring laboratory at Barrow, Alaska, and plans to do the same for stations in Eureka, Canada, and Tiksi, Russia. Such observatories are the only way to move forward with collecting the long-term data needed to monitor climate change.

The polar-year celebration represents, among other things, the best chance to get these climate-monitoring networks up and running. Let's hope that the funding difficulties are ironed out in time, and that this opportunity is used to produce a legacy worthy of International Polar Year 2007. 